\title{
Beta thalassemia and role of herbals and hematopoietic stem cells in its remedy
}

\begin{abstract}
Genetic disorders caused by mutations in the $\beta$-globin gene are widely known as the human $\beta$-hemoglobinopathies, in which there is $\beta$-thalassemia. In recent years, effort has been made to identify the natural inducers and drug treatments which can increase the synthesis of fetal hemoglobin and promote the expression of fetal $\gamma$-globin gene. This review aims to reveal the novel screening platforms for identifying potential herbal inducers with high efficiency and accuracy and to describe the hematopoietic stem cells remedies to provide perspectives in fetal hemoglobin reactivation for treating $\beta$-thalassemia.
\end{abstract}

Volume 6 Issue 5 - 2018

Pooja Rai, Kamal Uddin Zaidi,Vijay Thawani
Peoples University, India

Correspondence: Kamal Uddin Zaidi, Biotechnology Pharmacology Laboratory CSRD, Peoples University, Bhopal, (M.P) 462037, India, Email Zaidi.kamad92@gmail.com

Received:June 15, 2018| Published: October 18, 2018

Keywords: hematopoietic, herbals, disease, therapy, hemoglobin

\section{Introduction}

The thalassemia syndromes are inherited disorders of globin synthesis. These are considered as the world's most widespread genetic diseases. ${ }^{1}$ Beta-thalassemia comprises of a heterogenous group of hemoglobin disorders characterized by reduction or complete absence of $\beta$-globingene expressionand is inherited as an autosomal recessive disease. ${ }^{2,3}$ Thalassemia has spectrum of manifestations, ranging from asymptomatic nature to severe disease requiring frequent packed red blood cell (RBC) transfusions. ${ }^{4}$ Iron overload is a common problem with frequent blood transfusions in thalassemia major and inter media (TI) ${ }^{5,6}$ Thalassemia minor is a carrier state in which only one allele is mutated which can manifest in subsequent generation on marrying a partner of thalassemia minor or major. It has been debated as to whether $\beta$-thalassemia minor has increased iron absorption. ${ }^{7,8}$ Betathalassemia syndromes describe a group of genetic blood disorders caused by decreased or absent synthesis of the $\beta$-globin chain, resulting in reduced amount of hemoglobin in RBC, low RBC production and anemia. ${ }^{9}$ The intensiveness of $\beta$-thalassemia is associated with the extent of alpha and non-alpha globin chains imbalance. ${ }^{10}$ Its three main formsare $\beta$-thalassemia minor, $\beta$-TI and $\beta$-thalassemia major. B-thalassemia minor patients have no symptoms and the patient may lead a normal life. Patients with $\beta$-TI have moderate anemia whereas beta-thalassemia major patients have severe anemia and require frequent blood transfusions. ${ }^{9}$

\section{Life expectancy and mortality in $\beta$-thalassemia in Indian population}

The life expectancy of patients with thalassemia major has significantly increased in recent years, as reported by several researchers from different countries. However, complications are still frequent which affect the patients' quality of life. In a recent study from the UK, it was found that $50 \%$ of the patients died before the age of $35 y$ years. At that age, $65 \%$ of the patients from an Italian study were still alive. Heart disease is responsible for more than half of the deaths. ${ }^{4}$ The prevalence of complications in Italian patients born after 1970 included heart failure in $7 \%$, hypogonadism in $55 \%$, hypothyroidism in $11 \%$, and diabetes mellitus in $6 \%$. Similar data were reported in patients from the US. In the Italian study, lower ferritin level was associated with a lower probability of experiencing heart failure and with prolonged survival. Osteoporosis and osteopenia affected virtually all the patients. Hepatitis $\mathrm{C}$ virus antibodies were present in $85 \%$ of multi transfused Italian patients, $23 \%$ of UK, $35 \%$ of US, $34 \%$ of France, and $21 \%$ of Indian patients. Hepatocellular carcinoma can complicate the course of hepatitis. A survey of Italian centers identified 23 such cases in patients with a thalassemia syndrome. ${ }^{4}$

\section{Treatment of $\beta$-thalassemia}

Blood transfusions: These can replenish hemoglobin and RBC levels. Patients with thalassemia major need between eight and 12 transfusions a year. Those with less severe thalassemia need upto eight transfusions/year, or more in times of stress, illness, or infection. ${ }^{11}$

Iron chelation: This involves removing excess iron from the bloodstream. Sometimes blood transfusions can cause iron overload which can damage the heart and other organs. Patients may be prescribed deferoxamine, a medication that is injected under the skin, or deferasirox orally. Patients who receive blood transfusions and chelation may also need folic acid supplementation. It helps in RBC development. $^{12}$

Gene therapy: Scientists are investigating genetic interventions to treat thalassemia. Possibilities include inserting a normal beta-globin gene into the patient's bone marrow, or using drugs to reactivate the genes that produce fetal hemoglobin. ${ }^{13}$

\section{Use of herbals in $\beta$-thalassemia}

Herbs help in getting rid of thalassemia symptoms naturally. Herbal remedies are safe and may be taken on a regular basis. Herbs help to boost up the immunity. Herbs also reduce weakness and help to get rid of recurrent infection. Herbal remedies help in the formation of healthy RBCs.

Kumara-Kalyana Rasa: It is a natural herbal remedy that helps to get rid of thalassemia symptoms, formation of RBCs, boosting up the energy, getting rid of weakness, boosting the immune system and getting rid of recurrent infections. This is a herbal treatment to prevent recurrent infections in the body. ${ }^{14}$

Pravala Pisti: This is a natural herbal solution to get rid of anemia. It helps in the formation of protein that helps in making healthy RBCs. It boosts the immune system and helps to reduce weakness in the body. It boosts the energy and improves other symptoms of thalassemia. ${ }^{14}$ 
Kaharava Pisti: This is herbal remedy for the natural treatment of thalassemia. It helps in the formation of healthy RBCs. It reduces weakness and helps to get rid of other symptoms. It helps in the proper circulation of blood throughout the body. ${ }^{14}$

Moti Pisti: This herbal remedy is a wonderful solution to prevent the symptoms of thalassemia. It may be taken regularly to help in the formation of healthy RBCs. It also helps in making healthy protein for the formation of hemoglobin. It reduces the risk of developing thalassemia. It may be taken regularly to prevent the complications of the disease. ${ }^{14}$

Giloy Sattva: It is a useful herb that has been used traditionally for the treatment of any kind of blood disorders. It helps to get rid of anemia and makes the body healthy. It helps in the formation of RBCs. It increases the blood supply to all parts of the body and helps in the normal functioning of all the body organs. ${ }^{14}$

Pravala Pancamrta: It is an herbal remedy to get rid of thalassemia. It promotes healthy functioning of the body. It helps in the formation of RBCs and also produces protein. ${ }^{14}$

Other herbals: In recent years, researcher shave identified the herbal remedies that could be used in treating $\beta$-hemoglobinopathies, including sickle cell disease (SCD) and $\beta$-thalassemia. The extract of Aegle Marmelos containing bergatene activated erythroid differentiation and $\mathrm{HbF}$ induction in human leukemic K562 cells. ${ }^{15,16}$ Citropten and bergatene are the active ingredients in bergamot juice. They are powerful inducers of erythroid differentiation, $\gamma$-globin gene expression and $\mathrm{HbF}$ synthesis in human erythroid cells. This is a potential therapeutic approach for both $\beta$-thalassemia and SCD. ${ }^{16}$ Nicosan an ethanol/water extract from Nigerian indigenous plants, has significant anti-sickling effects in vitro and in vivo. ${ }^{17,18}$ Angelicin can be found in the fruit of Angelica arcangelica. It is a powerful inducer of erythroid differentiation, enhances $\mathrm{HbF}$ synthesis in erythroid progenitors and $\gamma$-globin mRNA accumulation of human leukemia K562 cells. ${ }^{19,20}$ Red wine, especially the skin of grapes, contains resveratrol which mimics the HbF-inducing activity of hydroxyurea. ${ }^{19}$ Its function in increasing the $\gamma$-globin mRNA in human erythroid precursors has been confirmed. ${ }^{19}$ Since $\beta$-thalassemia cells exhibit a higher level of oxidative stress, which eventually shortens the survival of erythroid cells in $\beta$-thalassemia patients, resveratrol which exhibits both antioxidant activity and $\mathrm{HbF}$ inducing property can become a very promising $\mathrm{HbF}$ inducer from the natural world. ${ }^{21}$

Rapamycin extracted from Streptomyces hygroscopicus, a bacterial species, has being found in the soil of Easter Island. It showed the ability to increase $\mathrm{HbF}$ production in cultures of erythroid precursors from $\beta$-thalassemia patients without cytotoxicity or growth-inhibitory effect. ${ }^{19,22}$ On the other hand, in Streptomyces species, mithramycin can be easily isolated. It is a DNA-binding drug which probably induces $\gamma$-globin mRNA accumulation and $\mathrm{HbF}$ production in erythroid cells from healthy humans as well as $\beta$-thalassemia patients. ${ }^{23}$ Indian almond (Terminaliacatappa), has long been used traditionally for SCD in Nigeria. It has been demonstrated that Terminaliacatappa distilled water active fraction (TCDWF) from leaves exhibit a stimulatory effect on the $\mathrm{HbF}$ production in primary erythroid prohenitor stem cells (EPSCs). ${ }^{24}$ Terminaliacatappa consists of flavonoids, alkaloids, and anthraquinones. Gas chromatography-mass spectrometry (GCMS) showed that a group of highly related long-chain fatty acids, viz. hexadecanoic acid, 10-octadecenoic acid, and octadecenoic acid, are present in the TCDWF. ${ }^{24}$ Further investigations are required in order to confirm the biological activities of these active compounds present in the TCDWF.

\section{Chinese herbs}

The Chinese herbal medicine, YiSuiShengXue Granule (YSSXG), a complex prescription made up of 11 Chinese herbal medicines, was effective in enhancing the $\mathrm{HbF}$ expression and inhibiting ineffective hematopoiesis. ${ }^{25-27}$ Research further confirmed its ability to increase $\gamma$-globin gene expression and alter the expression of genes that are involved in the survival, proliferation, and terminal differentiation of erythroid cells. ${ }^{25}$ Researchers found that cucurbitacin D in a Chinese medicinal herb, called Fructu strichosanthis (FT), exhibits a higher potency in $\mathrm{HbF}$ induction compared with hydroxyurea and there is evidence that cucurbitacin D causes an elevated fetal cell percentage and greater $\mathrm{HbF}$ content in K562 cells with much lesser cytotoxicity. ${ }^{26}$

Modern treatments include blood transfusion, treatment with hydroxyurea and stem cell transplants. Genetic engineering to repair the defective gene is being hoped for the solution. Treatment with Chinese medicine is of interest as it may help in blood disorders, such as SCD, that involves genetic defects in hemoglobin resulting in impairment of the blood. ${ }^{25}$ According to the Chinese traditional descriptions, the renal system is the source of the bone marrow that produces blood cells. The kidney and marrow store the essence that is present at birth and that is affected by prenatal factors. Tonifying the kidney essence is the basic principle of therapy to be used. The herbal therapy has been called BushenShengxue Fang or, BusuiShengxue Fang, or YisuiShengxue. ${ }^{26}$

Scientists have been investigating treatment of $\beta$-thalassemia. Chinese group has described administration of a capsule containing rehmannia, tortoise shell gelatin, donkey hide gelatin, cornus, and other herbs in children aged 5-14years with $\beta$-thalassemia. The dosage was 3-4 capsules at one time, 3 times daily, for 2 months. The authors reported improvement in hemoglobin levels and through studies of RNA suggested that transcription of RNA was enhanced and the gene defect was somewhat compensated for. The therapy was said to be effective for those with $\beta$-thalassemia minor, but not for those with $\beta$-thalassemia major.

In a follow-up study with 17 patients having $\beta$-thalassemia minor treated during 3 months starting October 1998, this group described the therapy as containing 12 ingredients, including cornus and millettia. They concluded that 16 cases improved as the symptoms were ameliorated; hepatosplenomegaly decreased; hemoglobin was significantly elevated; and no side effects were observed. They concluded that the positive effect of the herbs on this disease confirmed the traditional Chinese medicine theory that the kidney nourishes the marrow, and emphasized that the mechanism of action was at the level of the DNA, unlocking the gamma-gene, stimulating mRNA expression of gamma-globin, and inducing synthesis of hemoglobin to compensate for the defect of the beta-gene. ${ }^{27}$

\section{Thalessemia treatment using stem cell therapy}

Stem cells are the mother cells that are responsible for developing an entire human body from a tiny two celled embryo; due to their unlimited divisions and strong power to differentiate into all the cells of different lineage. This power of stem cells has been harnessed to isolate them outside the human body, concentrate in the clean environment and implant back. Thus, stem cell treatment involves administration of concentrated cells in the targeted area to form 
colonies; a characteristic of stem cells, adapt the properties of resident stem cells and initiate some of the lost functions that have been compromised due to disease or injury. ${ }^{28}$

Studies suggest that stem cells obtained from matched allogenic donor can be very effective and reverse the condition back to normal The child has to undergo complete destruction of his/her own bone marrow and undergo infusion of bone marrow stem cells from allogenically matched donor. The haematopoietic stem cells and some percentage of mesenchymal stem cells are found to be effective in complete replacement of total bone marrow with the healthy cells, due to their regenerative power. It has been suggested that the population of mesenchymal stem cells homes-in damaged areas to give rise to different organ specific cells, which have been damaged to restore back their function..$^{28}$

\section{Lacking in treatment of thalassemia in India}

India has the largest disease burden for thalassemia. Every month, there are over 40million carriers and 100,000 thalassemia majors receiving blood transfusion. Thalassemia patients continue to grow. No move has been made to have a prevention and control program at the national level. Thalassemia carriers are unintentionally passing this genetic disorder to their children due to lack of education, awareness, genetic counseling, and preventative screening. Government and nongovernmental organizations are taking some measures to address the importance of Thalassemia screening and counseling, but community control is challenging. Hence, it is difficult to initiate a national programme reaching all rural regions where almost $70 \%$ of our population resides.

\section{Conclusion}

The thalassemia syndromes are inherited disorders and the children suffering from this live poor quality of life which is not healthy and has shorter life span. Various interventions like herbals and hematopoietic stem cells have been tried in its remedy but none seems to provide the cure for it. The affected continue to suffer and unfortunately die an early death. It is advisable that in India where marriages are arranged and birthday horoscopes of the two partners matched prior to marriage, matching of thalassemia trait be made compulsory so that marriage among two minors, minor and intermediate/major can be prevented and future generation saved from this fatal disease. A national programme to control and prevent thalassemia is initiated in India to ensure the control of the disease.

\section{Acknowledgements}

None.

\section{Conflict of Interest}

The authors declare that there is no conflict of interests regarding the publication of this review.

\section{References}

1. Weatherall DJ, Clegg JB. The thalassemia syndromes. 3rd ed. Oxford: Blackwell Scientific Publications; 1981.

2. Savage DA, Wood NA, Bidwell JL, et al. Detection of b-thalassemia mutations using DNA hetero duplex generator molecules. $\mathrm{Br} J$ Haematol. 1995;90(3):564-571.

3. Filon D, Oron V, Krichevski S, et al. Diversity of b globin mutations in
Israeli ethnic groups reflects recent historic events. Am J Hum Genet. 1994;54:836-843.

4. Borgna-Pignatti C, Gallanello R. Thalassemias and related disorders: quantitative disorders of hemoglobin synthesis. In: Greer JP, Rodger GM, Foerster J, Paraskeves F, Lukens JN, Glader B, editors. Wintrobe's Clinical Hematology. 12th ed. New York: Lippincott Williams \& Wilkins; 2009:1083-1131.

5. Lin CK, Lin JS, Chen SY, et al. Iron absorption in hemoglobin $\mathrm{H}$ disease. Chin Med J. 1992;49:76-80.

6. Mehta BC, Pandya BG. Iron status of beta thalassemia carriers. Am J Hematol. 1987;24(2):137-141.

7. Dolai TK, Nataraj KS, Sinha N, et al. Prevalence of iron deficiency in thalassemia minor: A study from tertiary hospital. Indian J Hematol Blood Transfus. 2012;28(1):7-9.

8. Galanello R, Origa R. Beta-thalassemia. Orphanet J Rare Dis. 2010;5:11.

9. Cao A, Galanello R. Beta-thalassemia. Genet Med. 2010;12(2):61-76.

10. Rachmilewitz EA, Giardina PJ. How I treat thalessemia. Blood. 2011;118(13):3479-3488.

11. Ganz T. Hepcidin and iron regulation, 10 years later. Blood. 2011;117(17):4425-4433

12. Stein R. Gene therapy for inherited blood disorder reduced transfusions. USA: Health News from NPR; 2018.

13. Health natural care. 2018.

14. Li H, Ko CH, Tsang SY, et al. The ethanol extract of Fructus trichosanthis promotes fetal hemoglobin production via p38 MAPK activation andErk inactivation in K562 cells. Evid Based Complement Alternat Med. 2011;2011:657056.

15. Guerrini A, Lampronti I, Bianchi N, et al. Bergamot (Citrus bergamia Risso) fruit extracts as $\gamma$-globin gene expression inducers: phytochemical and functional perspectives. J Agric Food Chem. 2009;57(10):4103-4111.

16. Iyamu EW, Turner EA, Asakura T. In vitro effects of NIPRISAN (Nix0699): a naturally occurring, potent antisickling agent. Br J Haematol. 2002;118(1):337-343.

17. Iyamu EW, Turner EA, Asakura T. Niprisan (Nix-0699) improves the survival rates of transgenic sickle cell mice under acute severe hypoxic conditions. Br J Haematol. 2003;122(6):1001-1008.

18. El-Beshlawy A, Hamdy M, El Ghamrawy M. Fetal globin induction in Bthalassemia. Hemoglobin. 2009;33(Suppl 1):S197-S203.

19. Lampronti I, Bianchi N, Borgatti M, et al. Accumulation of $\gamma$-globin mRNA in human erythroid cells treated with angelicin. Eur J Haematol. 2003;71(3):189-195.

20. Gamabari R. Novel trends for the discovery and characterization of modifiers of globin gene expression. Proceedings of the $10^{\text {th }}$ International Thalassemia Conference. Egypt: Cairo; 2009.

21. Bianchi N, Zuccato C, Lampronti I, et al. Fetal hemoglobin inducers from the natural world: a novel approach for identification of drugs for the treatment of $\beta$-thalassemia and Sickle-cell anemia. Evid Based Complement Alternat Med. 2009;6(2):141-151.

22. Fibach E, Bianchi N, Borgatti M,et al. Mithramycin induces fetal hemoglobin production in normal and thalassemic human erythroid precursor cells. Blood. 2003;102(4):1276-1281.

23. Aimola IA, Inuwa HM, Nok AJ, et al. Induction of foetal haemoglobin synthesis in erythroid progenitor stems cells: mediated by water- 
soluble components of Terminaliacatappa. Cell Biochem Funct. 2014 Jun;32(4):361-367.

24. Zhang $\mathrm{C}$, Wu Z. Molecular pharmacological basis of the YiSuiShenXu Granule in $\beta$-thalassemia therapy. J of Ethnopharmacology. 2008;120(3): 437-441

25. Liu K, Xing H, Zhang S, et al. Cucurbitacin D induces fetal hemoglobin synthesis in K562 cells and human hematopoietic progenitors through activation of p38 pathway and stabilization of the $\gamma$-globin mRNA. Blood Cells Mol Dis. 2010;45(4):269-275.
26. Wu ZK, Zhang XH, Li M. Clinical observation on effects of YisuiShengxuegranule in treating 156 patients with beta-thalassemia. Zhongguo Zhong Xi Yi Jie He Za Zhi. 2006;26(4):352-354.

27. Shabeenataj S, Lakshmi Priya. Stem cell therapy for Thalassemia: A review. Int J PharmTech Res. 2014;6(4):1306-1308.

28. DorcasA. Why is Thalassemia a growing concern in India. Health Watch; 2018. 